\section{A METODOLOGIA DA PROBLEMATIZAÇÃO NA FORMAÇÃO DE REEDITORES AMBIENTAIS: CONCEITOS, CONTEXTOS E POSSIBILIDADES}

\author{
THE PROBLEMATIZATION \\ METHODOLOGY IN THE FORMATION \\ OF ENVIRONMENTAL REEDITORS: \\ CONCEPTS, CONTEXT AND \\ POSSIBILITIES
}

Luiz Ricardo Oliveira Santos

Rosemeri Melo e Souza

Jailton de Jesus Costa

\section{Resumo:}

A metodologia da problematização parte da observação da realidade concreta de determinada comunidade e culmina em intervenções que gerem uma resposta positiva à situação observada, modificando a visão dos discentes envolvidos no processo, instigando ações de cidadania. O presente estudo tem por objetivo discutir a relação entre a metodologia da problematização e a formação de reeditores ambientais. Para tanto, foram realizados levantamentos bibliográfico e documental, sendo consultadas políticas ambientais e educacionais, livros e artigos digitais e analógicos. Os educandos formados por esse processo podem se tornar reeditores ambientais ao passo que são estimulados a interagir com os aspectos socioambientais das comunidades, adaptando o conhecimento construído ao longo da formação à sua realidade. Assim, observa-se as múltiplas dimensões da Educação frente à formação ativa dos educandos e à construção de sociedades sustentáveis.

Palavras-chave: Arco de Maguerez. Educação Ambiental. Metodologias Ativas.

\begin{abstract}
:
The problematization methodology parts from the observation of a specific community's concrete reality and it culminate in interventions that generate a positive response to the observed situation, modifying the view of the students involved in the process, instigating citizenship actions. The objective of the present study is to discuss the relation between the problematization methodology and the environmental reeditors formation. For this purpose, bibliographic and documental surveys were done, with educational and environmental politics, books and both digital and physical articles been consulted. The learners formed by this process may become environmental reeditors as they are stimulated to interact with the socioenvironmental aspects of the community, adapting the knowledge built during their training. Thus, the multiple dimensions of the Education ahead of the active training of the learners and the construction of sustainable societies are observed.
\end{abstract}

Key words: Maguerez's Arch. Environmental Education. Active Methodologies. 


\section{LA METODOLOGÍA DE LA PROBLEMATIZACIÓN EN LA FORMACIÓN DE REEDITORES AMBIENTALES: CONCEPTOS, CONTEXTOS Y POSIBILIDADES}

\section{Resumen:}

La metodología de la problematización parte de la observación de la realidad concreta de una determinada comunidad y culmina en intervenciones que generen una respuesta positiva a la situación observada, cambiando la visión de los discentes involucrados en el proceso, instigando acciones de ciudadanía. Este estudio tiene como objetivo discutir la relación entre la metodología de la problematización y la formación de reeditores ambientales. Para eso, han sido realizados un estudio bibliográfico y documental, consultando políticas ambientales y educacionales, libros y artículos digitales o impresos. Los educandos formados por ese proceso pueden tornase reeditores ambientales mientras son estimulados a interactuar con los aspectos socio ambientales de las comunidades, adaptando el conocimiento construido en la formación para su realidad. Así, se observan las múltiples dimensiones de la Educación frente la formación activa de los educandos y la construcción de sociedades sostenibles.

Palabras clave: Arco de Maguerez, Educación Ambiental, Metodologías activas.

\section{Introdução}

A Educação Ambiental (EA) se constitui como processo de formação cidadã no tocante à sensibilização quanto ao uso dos bens naturais e a posição da sociedade frente a processos políticos e participativos no desenvolvimento da sociedade. De acordo com Leff (2009) a EA assume um saber que prepara o indivíduo para a construção de uma nova racionalidade socioambiental, superando a crise, desesperança e alienação, de maneira que sejam permitidas novas formas de reapropriação do mundo e melhoria na convivência com os outros. Portanto, a EA não se diferencia dos demais processos educativos, uma vez que suas práticas se voltam à formação holística ${ }^{1}$ dos cidadãos, visando a tomada de decisão e enfrentamento de problemas por meio da construção de sociedades sustentáveis ${ }^{2}$.

Como forma de garantir a formação integral do cidadão, com ênfase nos estudos relacionados ao meio ambiente em espaços formais de ensino, os Parâmetros Curriculares Nacionais (PCN), trazem este tema como transversal, o qual deve perpassar por todos os componentes curriculares e não se caracterizar como disciplina específica e isolada, garantindo a discussão dos aspectos socioambientais, promoção da sensibilidade e, principalmente, fornecer subsídios para práticas interdisciplinares (BRASIL, 1997, 1999). No entanto, como ainda sugere a Política Nacional de Educação Ambiental (PNEA), é garantida a oferta de disciplinas em cursos que se voltem à discussão de aspectos metodológicos que visem a formação de sujeitos aptos a trabalhar com a especificidade ambiental em seus múltiplos campos (BRASIL, 1999).

A interdisciplinaridade, nesse sentido, pode ser entendida para além de uma reunião de várias áreas que conversam entre si sob a observação de um fato, objeto ou fenômeno, e sim como ideologias que se complementam na busca pela resolução de problemas e integração de saberes das mais variadas áreas, levando-se em consi-

1 De acordo com Araújo (1999), o holismo na Educação prioriza a formação do ser humano em sua totalidade, superando os paradigmas cartesianos-newtonianos. Nesse contexto, projeta experiências transdisciplinares, proporcionando o desenvolvimento da compreensão do universo como um todo.

2 Para Irving (2014, p. 35), sociedades sustentáveis são “[...] sociedades fluidas, capazes de adaptação, orientadas por suas especificidades culturais e sua maneira de interpretar o mundo e a natureza." 
deração os valores de todos os envolvidos como parte constitutiva do processo de ensino-aprendizagem, de forma que se complementem e sejam construídos constantemente.

Consoante Leff (2000), a interdisciplinaridade é um processo amplo, que transcende os campos de ensino e pesquisa, indo além das disciplinas científicas comuns, articulando-se entre os vários campos do saber. Ademais, tal processo também abriga as ações educativas em espaços não-formais, onde o contato direto com a natureza e com a comunidade fundamentam a interação entre múltiplos saberes. Desse modo, a interdisciplinaridade também pode ser caracterizada pela integração entre as várias disciplinas ou ciências, indo desde a simples comunicação de ideias à formatação de conceitos fundamentais.

As práticas interdisciplinares aportam-se também no pensamento complexo, contribuindo para estender (ou entender) os estudos e reflexões das ciências em conjunto, não apenas como objetos dissociados de seu contexto, mas também entendendo a essência dos sujeitos. Desprende-se, portanto, da forma positivista de conhecimento e abre espaço para a construção de novos limites conceituais, quebrando paradigmas científicos de simplificação de saberes não só da área ambiental, mas também em todas as esferas (MORIN, 2011).

Outrossim, as atuais demandas da sociedade, que buscam por cidadãos críticos e capazes de resolver problemas de maneira hábil, podem ser mais facilmente resolvidas através de metodologias ativas, inovadoras e participativas, nas quais os educandos interagem com os processos de aula, que tendem a ter uma dinâmica diferenciada, considerando seus valores culturais, fundamentados nas características locais, e associando os conteúdos ao cotidiano da comunidade urbana/ rural em que a escola se insere de maneira contínua, gradativa e interdisciplinar.

Conforme reflexões acima mencionadas, o presente estudo tem por objetivo discutir a relação entre a Metodologia da Problematização com o arco de Maguerez e a formação de reeditores ambientais. Para atingir tal proposta, foram realizados levantamentos, tanto de natureza bibliográfica quanto documental, em bases indexa- das, sendo consultada a legislação ambiental, por meio da PNEA e documentos de orientação curricular, como os PCN. De igual forma, foram consultados artigos e livros analógicos e digitais que tiveram relação com as temáticas de EA e metodologias ativas.

Dessa forma, primeiramente, foi abordada uma discussão conceitual acerca de metodologias ativas e sua relação com as possibilidades de formação de reeditores ambientais, conceito esse abordado ao longo da discussão, que sua utilização potencializa. Em seguida, foram elucidadas as etapas em que se baseia a Metodologia da Problematização, sendo discutidos aspectos da EA que se relacionam com os instrumentos ativos da referida metodologia e a possibilidade de formação de reeditores ambientais como subsídio para incentivar e promover a criticidade, participação cidadã e a sustentabilidade ambiental.

\section{Reedição ambiental: construção crítica da ci- dadania e protagonismo discente por meio de metodologias ativas}

As metodologias ativas podem ser definidas como instrumentos de ensino-aprendizagem pautados na (re)construção e reflexão de estratégias que estimulem a criticidade do educando e os posicione ativamente para o enfrentamento de situações características da vida em sociedade, através da discussão de situações-problema . Em consonância com Costa et al. (2011, p. 14), "as metodologias ativas, diferentemente da pedagogia tradicional, situam os educandos no centro do processo pedagógico, como protagonistas de sua própria formação". Nessa perspectiva, ao associar o conteúdo do cotidiano, frente à realidade problematizada, é essencial que o educando tenha seus valores considerados no processo educativo, valorizando o conhecimento prévio como aporte para o diálogo. Assim, "[...] a aprendizagem se torna efetiva quando o conteúdo está presente no cotidiano dos educandos, sendo fundamental considerar o conhecimento que eles trazem da sua vivência e realidade" (FUJITA et al., 2016, p. 231).

Na sala de aula, é observada a utilização de procedimentos voltados à construção da autonomia discente, que são essenciais para o desenvolvimento cognitivo dos educandos, mas que, do 
ponto de vista da promoção à autonomia e (cri) atividade, ainda possuem insuficiências teóricas para serem caracterizados como metodologias ativas de ensino-aprendizagem, ao passo em que melhor sejam caracterizados como estratégias ou instrumentos de ensino. Segundo Paiva et al. (2016), tais procedimentos são observados sob a forma de seminários, trabalhos em equipe, pesquisas, dentre outros. Do mesmo modo, vale ressaltar que a utilização de tais instrumentos pelos professores é imprescindível como forma de transição entre o ensino tradicional e as novas metodologias de ensino pautadas no protagonismo discente.

As diferentes estratégias utilizadas na escola, por sua vez, apesar de inserir outras formas de abordagem, ainda têm no professor, o único idealizador dos encontros de aula e seu planejamento pode refletir pouca relação entre alunos-professor/professor-comunidade. Tais práticas, apesar de serem interessantes do ponto de vista pedagógico ao incentivar a comunicação e atividade dos docentes, refletem o principal idealizador e condutor do ensino. Com isso, ao analisar quem de fato seria recompensado ao ter seus objetivos propostos alcançados e que realidade seria modificada a curto prazo, pode-se questionar da seguinte forma: Quem propôs os temas dos seminários e seus objetivos? Caso os trabalhos não surtam os efeitos esperados, existirá reflexão sobre os motivos? Existe auto avaliação?

É possível imaginar que os seminários e trabalhos em grupo sigam estritamente o currículo e não incitem o aluno a buscar problemas associados à sua realidade, tampouco incentivam a comunicação entre estudantes e membros da comunidade da qual a escola faz parte. Pergunta-se, com isso, a quem a escola serve? Qual a formação dada aos alunos? Para qual sociedade os alunos são formados? Estão preparados para enfrentar as situações-problema a nível local, uma vez que exames de referência e a própria escola abordam características ambientais a nível global?

Nesse sentido, quando o professor tem dificuldade em ampliar o leque de informações pelo seguimento preciso do currículo tradicional, tendo em vista o desenvolvimento da matriz de exames de referência como o ENEM é provável que se encontre uma limitação em tratar de assuntos de escala local, esbarrando também na autonomia docente em selecionar e debater conteúdo dessa natureza, devido à limitação de carga horária e direcionamento curricular (SANTOS; COSTA, 2017; SANTOS; COSTA; MELO E SOUZA, 2017). Ainda segundo os autores, que abordam as implicações de exames de avaliação da Educação Básica, em temáticas socioambientais, é necessário dar vez e voz aos educandos e ampliar o debate para a escala local, visando a inserção deste recorte nos processos educacionais e no currículo escolar.

Contrapondo os estudos de Paiva et al. (2016), é viável que sejam diferenciadas metodologias ativas das já mencionadas estratégias de ensino, uma vez que é extremamente necessária a ampla fundamentação teórica acerca do objeto/sujeito de estudo por parte do professor que se propõe a trabalhar com tais metodologias, de forma que seja oferecido melhor aporte teórico, reorganização da infraestrutura escolar e aperfeiçoamento institucional e docente, visando a adaptação ao novo método de ensino.

Os fatos discutidos acima podem encontrar possíveis soluções quando os educandos são formados como protagonistas diante da reedição de valores socioambientais, cujo conceito parte da reflexão acerca da interpretação dos termos "disseminação" e "multiplicação", característicos dos estudos em EA. Pergunta-se, com isso: é viável que sejam formados disseminadores/multiplicadores de um conhecimento produzido em outras realidades? O processo de disseminar/multiplicar traz consigo apenas os êxitos das ações desenvolvidas?

O ideal na construção de saberes ambientais é que a partir do conhecimento global, tanto dos êxitos quanto das lacunas existentes, sejam adaptados os conceitos e práticas para que a Educação se torne significativa para determinada comunidade, garantindo a participação comunitária nas ações escolares e a construção do conhecimento local de maneira integrada para, assim, criar-se conhecimentos reais.

Essa integração entre o conhecimento escolar e os saberes populares, levando em consideração as interações sujeito-meio, é denominada abordagem relacional, na qual o contexto social da Edu- 
cação auxilia na busca pela superação da degradação socioambiental. Além disso, por relacionar a ciência aos saberes populares locais, através da interação entre conteúdos, devido à complexidade da temática, é que se deve integrar e reeditar o conhecimento ambiental de compreensão de mundo em todos os espaços de Educação de natureza formal ou não-formal (GUIMARÃES; VASCONCELLOS, 2006).

Nesse contexto, os reeditores ambientais são sujeitos holísticos, pautados na (re)formulação de conceitos e práticas que, pela característica ativa de sua formação, são capazes de enfrentar problemas da vida em sociedade, principalmente no tocante à sensibilização ambiental, de maneira crítica, criativa e participativa. Tal formação crítica permite ao reeditor ambiental considerar a coletividade como instrumento essencial para a construção da sociedade, fazendo com que os problemas das comunidades sejam externados e enfrentados, na busca pela cidadania. Assim, a capacidade de adaptar posturas e valores de determinado lugar, de maneira contínua, pautadas em participação e resolução de problemas são instrumentos essenciais para a reedição ambiental.

Com base nas premissas de formação de reeditores ambientais aqui expostas, é impossível dissociar o processo de formação de reeditores ambientais e adotar o que se tem na literatura enquanto multiplicação/disseminação de práticas e conceitos ambientais. A partir da observação da realidade local e da diversidade de problemáticas e saberes das comunidades envolvidas é que poder-se-á fazer uso da teoria pré-existente e adaptá-la à prática, criando, assim, novos conceitos. Portanto, para fins desse estudo e da observação do processo de formação de reeditores ambientais faz-se necessária a utilização de metodologias ativas eminentemente práticas, que façam uso da observação, do diálogo e que estimulem o senso crítico dos educandos, a exemplo da Metodologia da Problematização.

\section{Metodologia da problematização e protago- nismo discente}

O arco de Maguerez foi proposto por Charles Maguerez e difundido na primeira edição do livro "Estratégias de ensino-aprendizagem" de au- toria de Bordenave e Pereira (1989). No entanto, a obra pouco informou do histórico de Maguerez, sobre o qual pouco se sabe atualmente, bem de que maneira foi realizada a construção do arco. Mas, pesquisas iniciais sobre a metodologia pôde possibilitar que, no Brasil, a partir dos parâmetros do arco, a professora da Universidade Estadual de Londrina (UEL), Neusi Aparecida Berbel, utilizasse a metodologia em disciplinas do ensino superior, passando a ser denominada Metodologia da Problematização (BERBEL, 1998, 1999, 2011).

Em oposição à Educação bancária, esta já referenciada por outros teóricos, onde os princípios se aportam na transformação do indivíduo enquanto parte integrante do processo educacional de forma ativa e dialógica. Diante de uma situação-problema, o educando é instigado a tentar buscar sua resolução através de uma análise ampla e profunda, passando a ter uma visão global do processo (BORDENAVE; PEREIRA, 2008). Objetiva instigar o surgimento de outras maneiras de ensinar e aprender, dividindo a responsabilidade do processo entre discentes e docentes, substituindo a memorização de conteúdos e valorizando a construção do conhecimento pela associação entre teoria e prática de maneira indissociável (FUJITA et al., 2016).

Como mencionado, no Brasil, a referida metodologia é amplamente utilizada no Ensino Superior, com grande ênfase para os cursos da área de saúde (PAIVA et al., 2016), que ultimamente prima pela formação de profissionais capazes de resolver problemas da sociedade de maneira integrada, participativa e em conjunto com os demais profissionais da área assistencial. No entanto, estudos com aplicação dessa metodologia na Educação Básica e em áreas distintas à saúde, a exemplo da Educação Ambiental, ainda carecem de informações mais detalhadas e dedicação à pesquisa (SANTOS; MELO E SOUZA, COSTA, 2017).

Ainda segundo Bordenave e Pereira (2008), o diferencial da proposta de Maguerez, ilustrada por um arco (Figura 1), com cinco etapas, assim denominadas: observação da realidade; pontos-chave, teorização, criação de hipóteses de solução e aplicação à realidade, é o fato de o professor acompanhar mais de perto a aprendizagem do 
aluno em detrimento do conteúdo a ser ensinado ou das técnicas didáticas utilizadas, resultando o ensino como uma relação pessoal entre ambos. De igual forma, a utilização de métodos problematizadores permite que os educandos reflitam além da sua área de formação tradicional, permitindo o exercício da interdisciplinaridade (VIEIRA; PANÚNCIO-PINTO, 2015).

As etapas do arco são seguidas sequencialmente, pois a realidade observada na primeira etapa vai sendo estudada com profundidade para depois passar por um processo de intervenção. Assim, o processo deve partir de um problema de cunho físico ou social ao qual se encaixe a proposta de ensino-aprendizagem.

Figura 1: Arco de Charles Maguerez.

Arco da Problematização de Maguerez

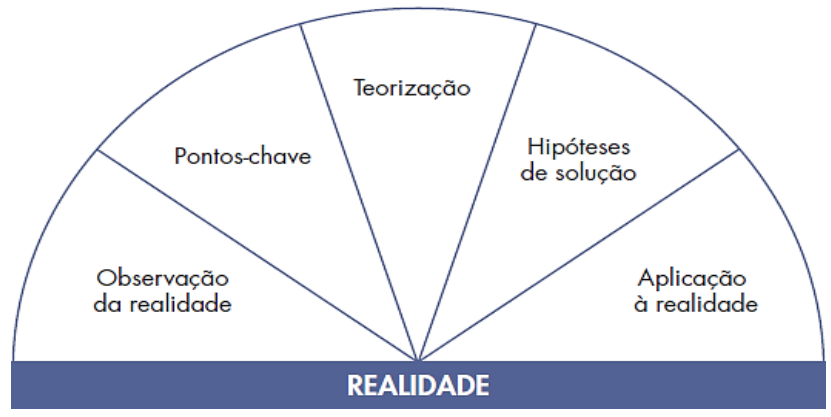

Fonte: Universidade Federal de Santa Catarina, s/d.

Observa-se na Figura 1 que o principal foco do arco é a realidade local, a qual interage com todas as cinco etapas de desenvolvimento da metodologia (BERBEL, 1998, 1999; BERBEL; GAMBOA, 2011). Contudo, o ato de problematizar exige mais que conhecer a realidade da comunidade e dos sujeitos dos quais se estuda, exige que tal realidade seja modificada e crie-se intervenções que tenham sentido real, através do diálogo coletivo, para além da academia (SAITO; FIGUEIREDO; VARGAS, 2014). Nesse sentido, as etapas do arco seguem abaixo discriminadas, mantendo relação com os critérios e possibilidades de formação de reeditores ambientais, conforme estudos descritos por SANTOS, MELO e SOUZA e COSTA (2017) e BERBEL (1998, 1999, 2011).
A primeira etapa do arco que configura a metodologia problematizadora, denominada observação da realidade, traz consigo a parte visual e a interação dos educandos com a comunidade, na qual se estabelecem os estudos. Através do contato inicial com a comunidade sobre a qual se quer compreender um referido problema, é que se pode visualizar e compreender suas necessidades, nesse caso em específico, as socioambientais. Para tanto, é possível que sejam utilizados instrumentos como fotografias, entrevistas e até mesmo conversas informais com os sujeitos, tendo em vista a aproximação e reconhecimento de seus pares.

Importante ressaltar que quando os sujeitos que desenvolvem o arco, aqui requerida pela formação de reeditores ambientais, têm uma relação de pertencimento e/ou identificação com o campo em que estão observando, essa tarefa pode se fazer muito mais prazerosa e facilitada, uma vez que adentrar em comunidades, as quais possuem valores culturais, afetivos, econômicos e sociais distintos pode demandar muito tempo. No entanto, quando não se é possível ter os sujeitos que pertencem à comunidade como observadores diretos, a interação inicial com lideranças comunitárias é de suma importância.

Na segunda etapa do arco, os educandos elencam os pontos-chave que lhes chamaram a atenção na observação. Podem ser reunidos os registros fotográficos, as entrevistas e a percepção dos mesmos quanto às interações entre a comunidade que foi visitada e os aspectos socioambientais da mesma. Qualquer objeto ou fenômeno que ocorra ou esteja em interação com os aspectos naturais ou sociais devem ser registrados, organizando os passos que serão estudados nas demais. No entanto, o professor deve manter o cuidado para que não interfira demasiadamente no processo de observação, evitando limitar os alunos à percepção de aspectos que o interessa somente enquanto docente/pesquisador.

A terceira etapa consiste na teorização, ou seja, a partir da observação da comunidade e dos sujeitos-foco do estudo e após elencar os principais pontos que a primeira etapa proporcionou, os educandos irão, de forma autônoma, direcionar os seus estudos e confrontá-los com a teoria existente na literatura em forma de livros, arti- 
gos, notícias, jornais, dentre outras fontes. O papel do educador, nesse momento, é direcionar os estudantes para que esses atinjam objetivos que eles mesmos desenvolveram e garantir que tais objetivos sejam alcançados da melhor forma, a fim de suceder as etapas posteriores com eficácia. Portanto, o educador tem por responsabilidade através do arco de Maguerez, de estimular os educandos a buscar teorias que fundamentem os seus estudos e forneça base teórica suficiente para fornecer subsídios para resolução da situação-problema por eles identificada.

Conforme afirma Pelicioni (2013, p. 472), "não existe EA apenas na teoria, o processo de ensino-aprendizagem, na área ambiental, implica o exercício de cidadania proativa". Logo, a EA não se diferencia dos demais processos educativos, compondo a formação holística e integral do ser humano, por meio da interdisciplinaridade, essa é inerente e dependente de múltiplos saberes que se integram. O educador ambiental, portanto, deverá ser um sujeito dotado de múltiplas habilidades e conhecimentos de diversas áreas da Ciência, garantindo uma Educação nos seus múltiplos âmbitos, seja ele socioambiental, político e até mesmo tecnológico, o que de fato pode encontrar melhor embasamento através da metodologia descrita nesse estudo.

Criar estratégias de solução que venham a elaborar processos interventivos para modificar a realidade socioambiental vigente, observada pelos educandos desde o desenvolvimento da primeira etapa do arco é a característica principal da quarta etapa da metodologia. Através das discussões com o grupo formado pelos demais estudantes que vivenciaram a realidade junto à comunidade e com base nos ensinamentos presentes na literatura consultada, os educandos podem pensar em ações interventivas que melhor se adaptem à realidade que deve estar nítida e presente não somente nesta etapa, mas em todas as demais. Importante ressaltar o papel do educador nesse momento, que deverá direcionar o grupo para a discussão e formulação de ações viáveis e ter o cuidado de não interferir de forma incisiva, retomando práticas tradicionais de ensino.

Nesse sentido, as práticas de educadores voltadas à EA problematizadora e questionadora inserem questões hoje emergentes na sociedade, de ma- neira contextualizada, na busca pela formação de agentes que transformem a realidade (GUIMARÃES et al., 2009). É viável ressaltar que tais práticas não devem ser apenas pautadas na disseminação/multiplicação de valores, mas que sejam capazes de criar/entender novas realidades, ou seja, formando agentes da reedição ambiental, que se caracterizam por manter aprendizado e reflexão contínuas e adaptáveis a diferentes contextos, pois mantém, na essência de sua formação, a valorização do diálogo e do enfrentamento coletivo de problemáticas.

A finalização do arco cabe à união de todas as etapas em um produto final: a intervenção condizente à situação real dos sujeitos e da comunidade da qual os educandos vivenciaram e fizeram parte durante o tempo em que se dedicaram aos estudos com a Metodologia da Problematização. Espera-se que, ao final de todo o processo, a intervenção realizada pelos educandos seja condizente com a realidade observada, a qual se analisa, ao mesmo tempo, dinâmica e dotada de interações entre discentes e comunidade, superando a prática tradicional acadêmica.

Como exemplificado na discussão acima, o objetivo principal da metodologia da problematização é partir da observação de um problema junto à comunidade e buscar o enfrentamento do mesmo através de ações de intervenção que se adaptem à mesma realidade, envolvendo os sujeitos que com ele lidam diariamente, fazendo-os percebê-lo e buscar melhorias de forma participativa e consciente. A Figura 2 sintetiza, conforme discutido nesse estudo, as etapas do arco, relacionando-as com os objetivos e/ou métodos e resultados esperados em sua aplicação para a formação de reeditores ambientais. 
Figura 2 - Organograma das etapas do arco de Maguerez e sua relação com a formação de reeditores ambientais.

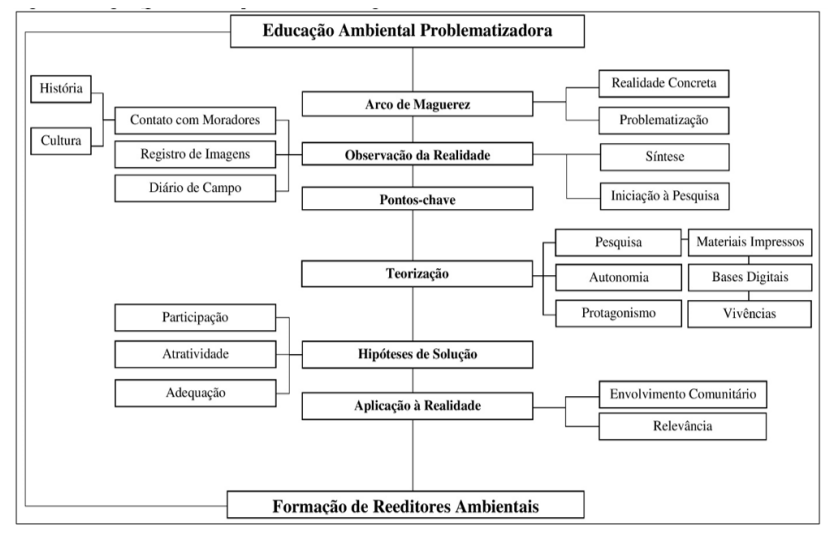

Fonte: Dados da pesquisa.

\section{Considerações finais}

A utilização de metodologias ativas, que abordam a realidade do lugar nos conteúdos escolares, é de essencial importância, tendo em vista a necessidade da problematização dos valores trazidos pelos educandos para o ambiente escolar. Nesse contexto, é necessário incentivar e garantir a formação de reeditores ambientais que apliquem o conhecimento construído ao longo da sua formação, principalmente à EA, ao contexto da sua realidade, evitando disseminar/multiplicar práticas, que não se inserem na realidade local e levem consigo também os problemas não enfrentados ou resolvidos, reforçados pela dificuldade imposta pelo seguimento do currículo tradicional escolar e exames de referência nacional.

Apesar de a metodologia da problematização ser mais utilizada no Ensino Superior e em cursos da área de saúde, por sua natureza interventiva e participativa, pode ser utilizada em outros âmbitos, inclusive no viés ambiental. Tendo em vista que a metodologia confere uma prática necessária para maior abrangência das características locais, distanciando os discentes do papel de mero espectadores, e considerando-os como protagonistas do seu aprendizado. Corrobora-se com Freire (1996), que o papel docente, sob esse aspecto, volta-se à lapidação dos conceitos trazidos à discussão pela vivência dos educandos, aperfeiçoando-os em um processo dialético de ensino.

Através de uma EA Problematizadora espera-se que seja observada com a interação entre discentes e comunidade e também na conversação entre discente/professor a promoção à sustentabilidade por meio da observação de sociedades sustentáveis. Assim, o processo de formação de reeditores ambientais está pautado na capacidade de transposição entre o que foi apreendido, com base nos ensinamentos locais, de maneira crítica, participativa e contínua, fazendo com que o educando seja capaz de desenvolver aspectos cognitivos que os coloque frente às necessidades diversas e os estimule a enfrentar situações-problema em qualquer escala espacial, pautados no respeito ao outro e na sensibilidade ambiental (SANTOS; MELO E SOUZA; COSTA, 2017).

\section{Referências}

ARAÚJO, Miguel Almir L. de. Abordagem holística na Educação. Sitientibus, Feira de Santana, n. 21, p. 159-176, jul./dez. 1999.

BERBEL, Neusi Aparecida Narvas. A problematização e a aprendizagem baseada em problemas: diferentes termos ou diferentes caminhos? Interface - Comunicação, Saúde, Educação, v. 2, n. 2, p. 139-154, fev., 1998.

Metodologia da Problematização: fundamentos e aplicações. Londrina, PR: EDUEL, 1999.

BERBEL, Neusi Aparecida Navas; GAMBOA, Sílvio Ancizar Sánchez. A metodologia da problematização com o arco de Maguerez: uma perspectiva teórica e epistemológica. Filosofia e Educação, v. 3, n. 2, p. 264-287, out/mar. 2011.

BORDENAVE, Juan Díaz; PEREIRA, Adair Martins. Estratégias de ensino-aprendizagem. 29. ed. Petrópolis, RJ: Vozes, 2008.

BRASIL. Lei no 9.795, de 27 de abril de 1999. Dispõe sobre a Educação Ambiental, institui a Política Nacional de Educação Ambiental e dá outras providências. Diário Oficial da República Federativa do Brasil, Brasília, DF, 27 abr. 1999. Disponível em: <www.planalto.gov.br/ccivil_03/ Leis/L9795.htm> Acesso em 19/09/2017.

Secretaria de Educação Fundamental. Parâmetros Curriculares Nacionais: meio am- 
biente e saúde. Brasília, 1997.

COSTA, José Roberto Bittencourt; ROMANO, Valéria Ferreira; COSTA, Rosane Rodrigues; GOMES, Andréia Patrícia; SIQUEIRA-BATISTA, Rodrigo. Active teaching-learning methodologies: medical students' views of problem-based learning. Revista Brasileira de Educação Médica, Brasília, v. 35, n. 1, p. 13-19. 2011.

FREIRE, Paulo. Pedagogia da autonomia: saberes necessários à prática educativa. São Paulo: Paz e Terra, 1996.

FUJITA, Júnia Aparecida Laia da Mata; CARMONA, Elenice Valentim; SHIMO, Antonieta Keiko Kakuda; MECENA, Elizane Henrique de. Uso da metodologia da problematização com o Arco de Maguerez no ensino sobre brinquedo terapêutico. Revista Portuguesa de Educação, Braga, v. 29, v. 1, p. 229-258. 2016.

GUIMARÃES, Mauro; SOARES, Ana Maria Dantas; CARVALHO, Néri Andréia Olabarriaga; BARRETO, Marcos Pinheiro. Educadores ambientais nas escolas: as redes como estratégia. Cadernos Cedes, Campinas, v. 29, n. 77, p. 4962, jan./abr, 2009.

GUIMARÃES, Mauro; VASCONCELLOS, Maria das Mercês N. Relações entre Educação Ambiental e Educação em Ciências na complementaridade dos espaços formais e não formais de Educação. Educar, Curitiba, n. 27, p. 147-162, 2006.

IRVING, Marta de Azevedo. Sustentabilidade e o futuro que não queremos: polissemias controvérsias e a construção de sociedades sustentáveis. Sinais Sociais, Rio de Janeiro, v. 9, n. 26, p. 1338, set./dez. 2014.

LEFF, Enrique. Complexidade, interdisciplinaridade e saber ambiental. In: PHILIPPI, Jr. et al. (Org.) Interdisciplinaridade em Ciências Ambientais. São Paulo: Signus Editora, 2000. Capítulo 2. p. 19-51.

. Complexidade, racionalidade ambiental e diálogo de saberes. Educação e Realidade. v. 34, n. 3, p. 17-24, set/dez, 2009.

MORIN, Edgar. Introdução ao pensamento complexo. 4. ed. Porto Alegre: Editora Sulina, 2011.

PAIVA, Marlla Rúbya Ferreira; PARENTE, José Reginaldo Feijão; BRANDÃO, Israel Rocha; QUEIROZ, Ana Helena Bomfim. Metodologias ativas de ensino-aprendizagem: revisão integrativa. Sanare. v. 15, n. 2, p. 145-153, jun./dez., 2016.

PELICIONI, Marília Cecília Focesi. Fundamentos de Educação Ambiental. In: PHILIPPI JR., Arlindo; ROMÊRO, Marcelo de Andrade; BRUNA, Gilda Collet. (Ed.) Curso de gestão ambiental. Barueri: Manole, 2013. p. 460 - 491.

SAITO, Carlos Hiroo; FIGUEIREDO, João Batista de Albuquerque; VARGAS, Icléia Albuquerque. Educação Ambiental numa abordagem freireana: fundamentos e aplicação. In: PEDRINI, Alexandre de Gusmão; SAITO, Carlos Hiroo (Org.). Paradigmas metodológicos em Educação Ambiental. Petrópolis, RJ: Vozes, 2014. p. 71-81.

SANTOS, Luiz Ricardo Oliveira; COSTA, Jailton de Jesus. Educação Ambiental e as Ciências da Natureza: desafios curriculares frente ao Exame Nacional do Ensino Médio. In: ENCONTRO INTERNACIONAL DE FORMAÇÃO DE PROFESSORES/FÓRUM PERMANENTE INTERNACIONAL DE INOVAÇÃO EDUCACIONAL, 10, 2017, Aracaju. Anais do 10 ENFOPE/11 FOPIE. Aracaju: Universidade Tiradentes, 2017. p. 1-15.

SANTOS, Luiz Ricardo Oliveira; MELO E SOUZA, Rosemeri; COSTA, Jailton de Jesus. A metodologia da problematização no contexto da Educação Básica: possíveis caminhos para a formação de reeditores ambientais. Cadernos de Estudos e Pesquisa na Educação Básica, Recife, v. 3, n. 1, p. 254-274. 2017.

SANTOS, Luiz Ricardo Oliveira; COSTA, Jailton de Jesus; MELO E SOUZA, Rosemeri. High School National Examination and its implications for Environmental Science Teaching. Revista 
Eletrônica em Gestão, Educação e Tecnologia Ambiental, Santa Maria, v. 21, n. 3, p. 232-239, set./dez. 2017.

UNIVERSIDADE FEDERAL DE SANTA CATARINA. Curso de especialização em Linhas de Cuidado em Enfermagem. S/D. Disponível em $<\quad$ https://unasus2.moodle.ufsc.br/pluginfile.php $/ 6808 / \mathrm{mod}$ resource/content $/ 3 /$ un $03 /$ top03p01.html> Acesso em: 16/05/2018 às $23 \mathrm{~h} 31 \mathrm{~min}$.

VIEIRA, Marta Neves Campanelli Marçal; PANÚNCIO-PINTO, Maria Paula. A metodologia da problematização (MP) como estratégia de integração ensino-serviço em cursos de graduação na área de saúde. Medicina, Ribeirão Preto, v. 48, n. 3, p. 241-248. 2015.

\section{Sobre os autores:}

Luiz Ricardo Oliveira Santos é Licenciado em Ciências Biológicas e Mestrando em Ensino das Ciências Ambientais pela Universidade Federal de Sergipe (UFS). Pesquisador vinculado ao Grupo de Pesquisa em Geoecologia e Planejamento Territorial (Geoplan/CNPq/UFS) e ao Grupo de Pesquisa e Ensino em Ciências Ambientais (GPECIAMB/UFS). E-mail: santos.lro@gmail. com

Rosemeri Melo e Souza é Doutora em Desenvolvimento Sustentável pela Universidade de Brasília. Docente da Universidade Federal de Sergipe, lotada no Departamento de Engenharia Ambiental e Sanitária, vinculada aos Programas de Pós-Graduação em Desenvolvimento e Meio Ambiente (PRODEMA), Geografia (PPGEO) e Engenharia e Ciências Ambientais (PPGECIA). Líder do Geoplan/CNPq/UFS. E-mail: rome@ ufs.br

Jailton de Jesus Costa é Doutor em Geografia. Docente da Universidade Federal de Sergipe, lotado no Colégio de Aplicação. Professor do PROF-CIAMB/UFS e PRODEMA/UFS. Pesquisador do Geoplan/CNPq/UFS. E-mail: E-mail: jailton@ufs.br / jaicosta.se@gmail.com 